\title{
Importance of Immunization in Child Care and Prevention
}

\section{Carlos Vallbona, M.D.}

ABSTRACT: This article stresses the importance of immunization in child care for prevention of many diseases. It discusses the reasons for the failure within the United States to eradicate many infectious diseases in children despite the availability of technology. Suggestions for action to improve this situation are made.

\section{Basic Concepts}

In a symposium devoted to obstacles and opportunities to the achievement of the Healthy People Year 2000 Objectives, it may be helpful to review a model of the evolution of any specific disease in an individual or a population group and the rationale for implementing preventive measures at different phases of this evolution.

The Hutchison's model, illustrated in Figure 1, identifies four critical points in the course of a disease (1). At the point of biologic onset A, biological changes are occurring but are not yet detectable by diagnostic tests. As changes progress to point B, they can be detected by means of diagnostic tests, but the patient has no manifest symptoms characteristic of the disease. At point $\mathrm{C}$, the patient has symptoms of the disease. From then on, depending on the nature of the disease and efficacy of treatment, the disease moves to the endpoint $\mathrm{D}$, which is either cure or death.

Primary prevention is an intervention before the biologic onset of disease. A typical example is the prevention of infectious diseases by vaccination. Secondary prevention is an intervention when disease can be detected at a stage before it is symptomatic. For example, a secondary prevention measure of AIDS is the screening for HIV infec-

\footnotetext{
Dr. Vallbona is Distinguished Service Professor and Chairman, Department of Community Medicine, Baylor College of Medicine, Houston, Texas. Address communications to the author at the college, One Baylor Plaza, Suite 650E, Houston, Texas 77030.
} 


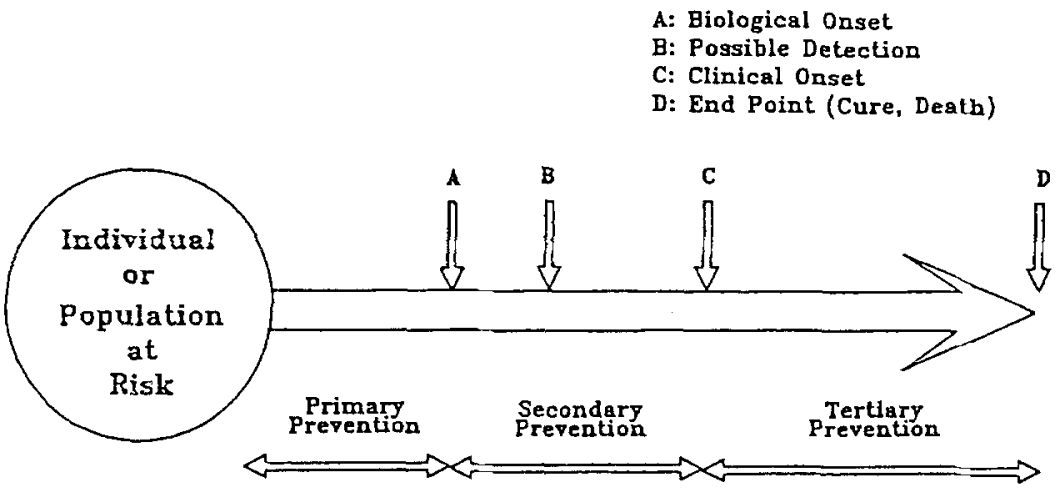

FIGURE 1. Hutchison's Model Phases of Prevention in relation to the evolution of a disease (Adapted from Hutchison GB: "Evaluation of Preventive Services." J. Chronic Dis. 11:497-508, 1960.)

tion in persons at high risk. Tertiary prevention defines an intervention after the onset of symptoms, in order to delay, arrest, or reverse the course of a disease or simply to prevent its complications. An example is the screening for early detection of retinopathy in juvenile diabetics.

This presentation focuses on the primary prevention of infectious diseases in children by means of appropriate vaccinations. Since it is well known that children may have congenital or acquired immunity (although usually the former is temporary), it may be argued from a purely theoretical point that before proceeding to immunize a child one should screen for antibody titers or other measurements of immunity. However, limiting the vaccination to those children who do not have adequate immunity at a certain time in their lives is not practical. Accordingly, the most prudent approach (indeed the only alternative currently available at the community level), is to follow the specific guidelines for vaccination of all children (except those for whom it is contraindicated) as proposed by the Immunization Practices Advisory Committee (ACIP) and the American Academy of Pediatrics. These guidelines are in agreement with the comprehensive Report of the Committee on Infectious Diseases of the American Academy of Pediatrics (2). Since 1938, the Academy has periodically published its recommendations in 22 editions of what is commonly referred to as the famous "Red Book" (10).

In spite of the well-established guidelines, the percentage of ade- 


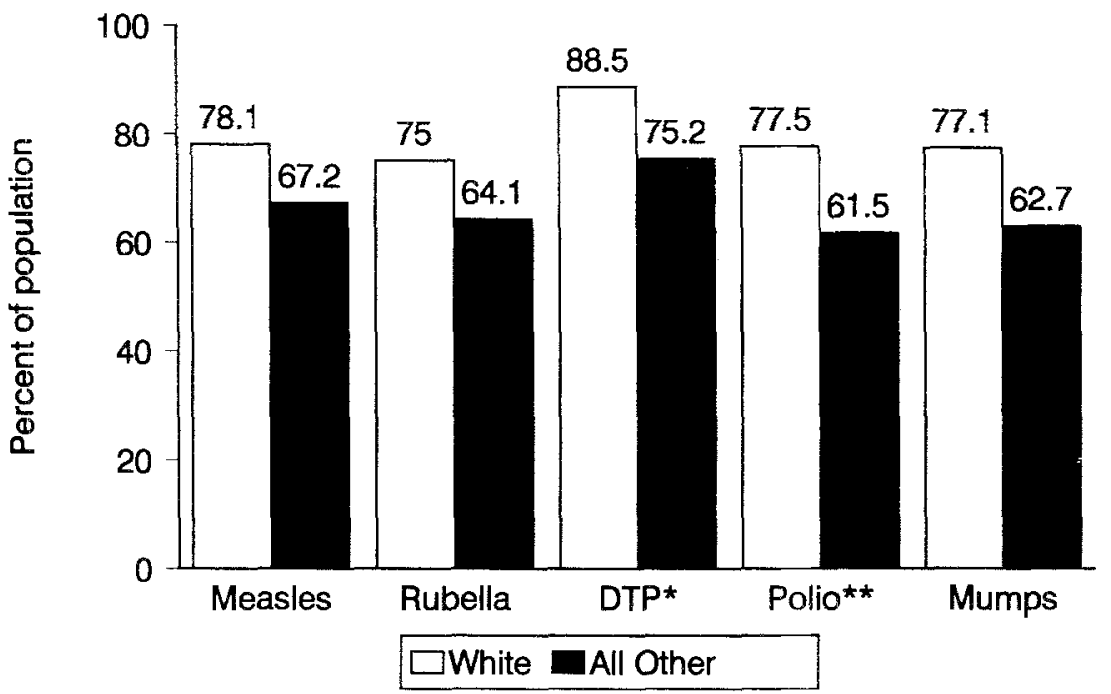

*Diphtheria-tetanus-pertussis. ** Three doses or more

FIGURE 2. Vaccinations of children 1-4 years of age for selected diseases: United States, 1985 (Source: National Center for Health Statistics. Health, United States, 1990. Hyattsville, Maryland. Public Health Service, 1991. Table 42.)

quately immunized preschool children in the United States is alarmingly low and lagging behind other industrialized nations. Figure 2 shows the national average of American preschool children who by age four in 1985 had completed the immunization requirements for specific illnesses (3). The overall U.S. average was about $88.5 \%$ for whites and $64 \%$ for all others. These averages are much lower than the $97 \%$ in the Netherlands and $80 \%$ in Norway. It is even more frightening to consider the totally unacceptable levels of immunization in some metropolitan areas. As an example, the CDC report of a retrospective study conducted in nine American cities showed that the percentage of children who had received at least 3 diphtheriatetanus-pertussis (DTP), 3 oral polio vaccine (OPV) and 1 measlesmumps-rubella (MMR) immunizations ranged from $40 \%$ in Houston to $61 \%$ in El Paso(4).

This explains why totally preventable infectious diseases have not been eradicated, in spite of the tools that we have at our disposal to 


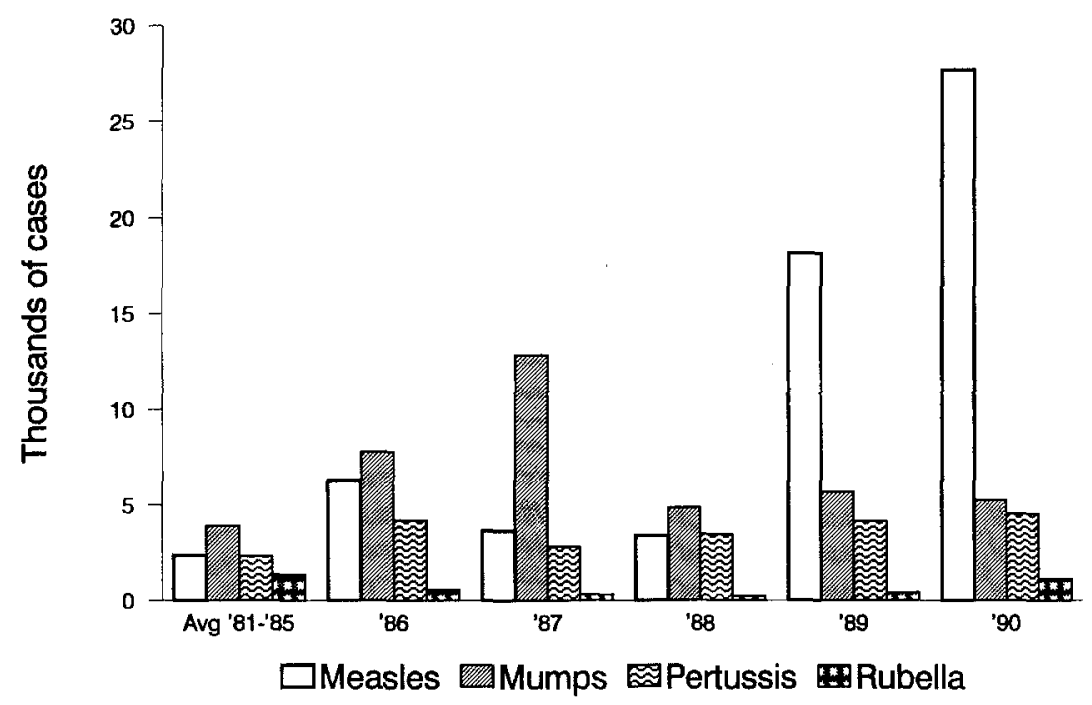

FIGURE 3. Incidence of vaccine-preventable diseases: United States, 1981-1990 (Source: Centers for Disease Control. Summary of Notifiable Diseases, United States, 1990. Morbidity and Mortality Weekly Report. 1990; 39[53]:55.)

accomplish this eradication. It also explains the recent outbreaks of measles, the most recent one having occurred in 1989-1991 (Figure 3) with a cumulative number of 27,786 cases reported in 1990 , causing a total of 89 deaths (5). Indeed, to reduce the threat of a particular infectious disease in a community it is necessary to achieve a certain level of what has been traditionally referred to as "herd immunity" (6). "Herd immunity" may be expressed as the percentage of children who through natural or acquired immunity or vaccination are not at risk of contracting an infectious disease. A recent study of the outbreak of measles which occurred in Milwaukee in 1989-90 showed a highly significant correlation between the incidence of measles in certain of the city's census tracts and the low level of herd immunity in the child population of those tracts(7). Furthermore, the study pointed out that in census tracts where the percentage of immunized children was only $70 \%$, the incidence of measles was negligible, thus suggesting that sufficient herd immunity may be achieved even if the percentage of immunized children is not as high as proposed in the Healthy Children 2000 objectives (8). 


\section{Specific Outcome Objectives in the Prevention of Infectious Diseases}

The book Healthy People 2000 has established the following specific objectives(9) as they pertain to preventable infectious diseases:

(a) Reduce indigenous cases of vaccine-preventable diseases from current levels to zero for diphtheria, tetanus, polio, measles, and rubella, and to no more than 500 cases of mumps and 1,000 cases of pertussis.

(b) Reduce the incidence rate of viral hepatitis $B$ from $63.5 / 100,000$ to $40 / 100,000$.

In order to reach these objectives, it is necessary to raise the current low levels of herd immunity. This can be accomplished by incorporating the guidelines proposed by Immunization Practices Advisory Committee (ACIP) and the American Academy of Pediatrics.

\section{Current Guidelines for Immunization Practices}

Table 1 provides a summary of the recommended immunization schedule for children and the type and dose for each vaccine (10).

The recommendations of the U.S. Public Health Service and the American Academy of Pediatrics differ for hepatitis B vaccine (HBV) immunizations for infants. The Public Health Service recommends immunization for infants at the same time as DTP immunizations (2, 4 , and 6 months of age). The American Academy of Pediatrics recommends that the first dose be given after birth before hospital discharge, with a second dose at 1-2 months of age and the third dose at 6-18 months of age(11) (Table 2).

It is hoped that the simultaneous administration of HBV with the DTP vaccine will simplify the immunization schedule without compromising the immunological response to the administration of combined vaccines.

\section{Barriers to Immunization}

As technology is available to immunize the population of children with minimum danger, relatively little discomfort and at a very high 


\section{Recommended Schedule for Immunization of Healthy Infants and Children}

\begin{tabular}{|c|c|c|}
\hline $\begin{array}{l}\text { Recommended } \\
\text { Age }^{\mathrm{a}}\end{array}$ & Immunizations & Comments \\
\hline 2 months & $\begin{array}{l}\text { Diphtheria, and tetanus } \\
\text { toxiods with pertussis } \\
\text { vaccine (DTP), Haem- } \\
\text { ophilus b conjugate } \\
\text { vaccine (HbCV) } \\
\text { poliovirus vaccine con- } \\
\text { taining attenuated } \\
\text { poliovirus types } 1,2 \text {, } \\
\text { and } 3(\mathrm{OPV})\end{array}$ & $\begin{array}{l}\text { DTP and OPV can be } \\
\text { initiated as early as } 4 \\
\text { weeks after birth in } \\
\text { areas of high endemi- } \\
\text { city or during epi- } \\
\text { demics }\end{array}$ \\
\hline 4 months & DTP $, \mathrm{HbCV}^{\mathrm{b}}, \mathrm{OPV}$ & $\begin{array}{l}\text { 2-month interval (mini- } \\
\text { mum of } 6 \text { weeks) de- } \\
\text { sired for OPV to avoid } \\
\text { interference from pre- } \\
\text { vious dose }\end{array}$ \\
\hline 6 months & DTP, $\mathrm{HbCV}^{\mathrm{b}}$ & $\begin{array}{l}\text { Third dose of OPV is not } \\
\text { indicated in the U.S. } \\
\text { but is desirable in } \\
\text { other geographic areas } \\
\text { where polio is endemic }\end{array}$ \\
\hline 15 months & $\begin{array}{l}\text { Live Measles, mumps, } \\
\text { and rubella viruses in } \\
\text { a combined vaccine } \\
(\mathrm{MMR}), \mathrm{HbCV}^{\mathrm{c}}\end{array}$ & $\begin{array}{l}\text { Tuberculin testing may } \\
\text { be done at the same } \\
\text { visit }\end{array}$ \\
\hline 15-18 months & $\mathrm{DTP}^{\mathrm{d}}, \mathrm{OPV}$ & \\
\hline $4-6$ years & $\mathrm{DTP}^{\mathrm{a}}, \mathrm{OPV}$ & At or before school entry \\
\hline $11-12$ years & MMR & $\begin{array}{l}\text { At entry to middle } \\
\text { school or junior high } \\
\text { school unless second } \\
\text { dose previously given }\end{array}$ \\
\hline $14-16$ years & $\begin{array}{l}\text { Adult tetanus toxoid } \\
\text { (full dose) and diph- } \\
\text { theria toxoid (reduced } \\
\text { dose) for adult use } \\
\text { (Td) }\end{array}$ & $\begin{array}{l}\text { Repeat every ten years } \\
\text { throughout life }\end{array}$ \\
\hline
\end{tabular}

\footnotetext{
aThese recommended ages should not be construed as absolute. However, MMR usually should not be given to children younger than 12 months.

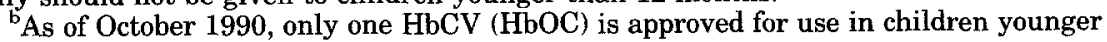
than 15 months.

${ }^{\mathrm{C}}$ Any licensed Haemophilus b conjugate vaccine may be given.

dMay be given simultaneously with MMR at 15 months.

eMay be given simultaneously with MMR and $\mathrm{HbCV}$ at 15 months or at any time between 12 and 24 months.
} 
TABLE 2

Recommended Routine Hepatitis B Immunization Schedules

\begin{tabular}{lcl}
\hline Maternal HBsAg Status & Dose & \multicolumn{1}{c}{ Age } \\
\hline Negative $^{\mathrm{a}}$ & 1 & $0-2$ days \\
& 2 & $1-2$ months \\
& 3 & $6-18$ months \\
Positive & $1^{\mathrm{b}}$ & 0 days \\
& 2 & 1 month \\
& 3 & 6 months \\
\hline
\end{tabular}

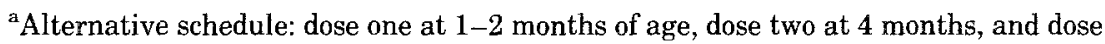
three at 6-18 months.

${ }^{b} \mathrm{HBIG}$ (hepatitis b immunoglobulin) should also be administered.
}

cost/benefit ratio, it is fitting that we analyze what obstacles have impeded the widespread and timely vaccination of preschool children.

The results of a Gallup Poll on parents' beliefs about immunization showed that although most parents surveyed had their children immunized, a high percentage believed other parents either did not obtain or maintain full immunization of their children because of the high cost $(48 \%)$ or lack of appreciation of the importance of immunization (36\%) (12).

Orenstein et al. discussed four key types of known barriers to successful vaccination(13): missed opportunities for administering vaccines, shortfalls in the health care delivery system, inadequate access and incomplete public awareness or motivation to ask for immunization.

The American Academy of Pediatrics, in its newsletter of August, 1991, suggested that the following barriers currently impede achievement of the hoped-for higher levels of herd immunity in the United States (14):

- awkward and inconvenient locations and hours at clinics where vaccinations are given;

- long waiting lines at these clinics;

- shortage of clinic personnel and resources;

- lack of education/awareness of the importance of timely vaccinations on the part of the parents; 
- cost;

- personal fears of inflicting or receiving "pain" and inadequate knowledge of the risks of vaccinations;

- lack of "walk-in" clinic vaccination facilities;

- requirements of physical examinations or physician referral before vaccination.

The increasing cost of vaccines has affected public health departments and private physicians alike (15). This is well illustrated by analyzing the differences in vaccine cost between 1982 and 1992 (16). In 1982, a dose of DTP cost the Federal government $\$ 0.15$. In 1992, it cost the Federal government $\$ 6.25$ and a private practitioner $\$ 9.97$. Polio vaccine was $\$ 0.47$ in 1982 and is now $\$ 2.00$ to the government and $\$ 9.45$ to the physician. MMR, too, has increased from $\$ 4.02$ to $\$ 15.33$ to the Federal government and $\$ 25.29$ to the private practitioner.

Religious beliefs are a potential barrier to herd immunity. This has been indicated as a contributing factor in four recent pertussis outbreaks that have occurred in Massachusetts (17).

Inadequate public awareness about the importance of immunization is evident in inner city, predominantly minority communities (18).

\section{Strategies for Action}

The book Healthy People 2000 (9) includes three specific Services and Protection Objectives which aim at improving the level of vaccination in U.S. children:

(a) Expand immunization laws for schools, preschools, and day care settings to all States for all antigens;

(b) Increase to at least $90 \%$ the proportion of primary care providers who provide information and counseling about immunizations and offer immunizations as appropriate for their patients;

(c) Improve the financing and delivery of immunizations for children and adults so that virtually no American has a financial barrier to receiving recommended immunizations.

It is clear that accomplishment of these service and protection objectives requires adoption of a variety of strategies. Some of them are 
quite obvious, such as campaigns of community education, but the strenuous efforts conducted thus far do not seem to have led to the necessary level of immunity because some obstacles such as accessibility and cost still remain. It is for this reason that the Texas Department of Health has proposed the following set of strategies (19):

- administer as many vaccines as possible at one clinic visit;

- avoid the "assembly line" trap;

- avoid the "dollar" barrier;

- discontinue the routine practice of immunizations by clinic appointment;

- increase or reschedule existing clinic hours to include evening clinics and weekend clinics;

- provide immunizations in alternative community settings;

- make sure communities know where and when immunizations are available at low or no cost for those who cannot afford them.

Those strategies are consistent with the set of recommendations made by the National Vaccine Advisory Committee as a result of its analysis of the recent measles epidemic (15). It is clear that the intent is to improve the public health departments' outreach to the community, but such efforts might not be too productive if there is inadequate mobilization of community groups and community resources as outlined in the following section.

\section{Opportunities for Action}

The United States has entered into a long overdue period of analysis of the pros and cons of adopting a national health program. Regardless of configuration and means of financing, any future health program must contain provisions to ensure the highest possible level of immunization in children. The Robert Wood Johnson Foundation, recognizing the need, has announced a program, "ALL KIDS COUNT" which will award funds to at least 12 communities that pledge to establish community-wide efforts to improve the immunization level of their preschool children (20). The Johnson Foundation has requested that communities applying for funds submit a "comprehensive plan for assuring immunization of preschool children, which 
should be tailored to the target community or population and should include the following activities:

1. Convening an advisory committee of public and private providers, public officials, and community leaders committed to reducing vaccine-preventable diseases, in order to guide the project's progress and keep it visible in the public and private sectors.

2. Clearly identifying the target population to be served.

3. Identifying all existing private and public immunization services and ways for improving access to and use of these services.

4. Identifying service gaps and barriers-including sociocultural barriers-and developing strategies to overcome them.

5. Identifying existing immunization record-keeping system that can be adapted or linked to regional, State, or Federal systems.

6. Determining how demographic and immunization data on all children under age 5 will be obtained and entered into the computer system and how it will be kept up-to-date.

7. Determining how these data will be analyzed and communicated to parents, providers, and public officials.

8. Establishing guidelines for maintaining confidentiality of client records.

9. Developing a system for follow-up (letters, phone calls, home visits) and referral.

10. Developing a financial plan that will enable the project to continue past the grant period.

11. Developing plans for institutionalizing the new system generated under the grant within ongoing State and local programs."

It is important to point out the importance attached by The Robert Wood Johnson Foundation to the establishment of linkages between immunization record-keeping systems at the community, State, and Federal levels. This is a prerequisite to the continuous surveillance of immunization status and the timely implementation of mass immunization campaigns when and where the herd immunity level is below certain thresholds. 
Lastly, we must indicate the opportunities for researchers to conduct the kinds of specific studies outlined in Healthy People 2000 (9):

- Development and introduction of new or improved vaccines including (acellular) pertussis, $H$. influenzae type $\mathrm{b}$, tuberculosis, respiratory syncytial virus, malaria, rotavirus, measles, $S$. pneumoniae, Group B streptococcus, measles, and parainfluenza virus type 3 ;

- Clarification of the relationship between whole-cell pertussis vaccines and serious neurologic reactions and investigation of possible adverse effects of vaccines;

- Evaluation of the effectiveness of a two-dose measles vaccine schedule;

- Elucidation and evaluation of the optimal schedule for combined use of inactivated and live poliovirus vaccines;

- Development and evaluation of rapid, sensitive, and specific diagnostic tests for measles and tuberculosis, as well as emerging infectious diseases such as Lyme disease;

- Development of effective immunoadjuvants to improve the efficacy of currently available vaccines for children, ... and the immunocompromised;

- Refinement of Streptococcus pneumoniae vaccine for use in infants and young children to prevent otitis media complications.

It is hoped that the community of healthcare practitioners, which is painfully aware of the need to ensure better levels of immunization in children, will accept the challenge offered by Healthy People 2000 and will seize the opportunity to achieve our ultimate goal which is the improvement of the state of health of all of our children.

\section{Conclusion}

In spite of the superb advances in health care technology and an equal excellence of some aspects of the American health care system, the U.S. population has not yet reached a state of health which could be attained through proper mobilization of community resources. The U.S. Department of Health and Human Services has established a series of national health promotion and disease prevention objectives. 
Outstanding among them is the improvement of the currently low levels of immunization of preschool children. The overall U.S. average of adequately immunized preschool children in the United States is about $65 \%$, which is much lower than the much higher levels achieved in other industrialized nations. Recent outbreaks of mumps and measles have pointed out the need to adequately immunize the preschool population. Since 1938, the American Academy of Pediatrics has proposed specific guidelines for the immunization of preschool children and, more recently, the Immunization Practices Advisory Committee has developed specific guidelines for all health care practitioners. In spite of this, we have to remove 4 key types of known barriers to successful vaccination: missed opportunities for administering vaccines; shortfalls in the health care delivery system; inadequate access; and incomplete public awareness. Strategies for action have been proposed by numerous professional organizations and community groups. It is hoped that the community of health care practitioners, which is painfully aware of the need to insure better levels of immunization in children, will accept the challenge offered by Healthy People 2000 and will seize the opportunity to facilitate the implementation of the proposed strategies. The ultimate goal is the improvement of the state of health of all of our children and the $\mathrm{Na}$ tional Academies of Practice are in a unique position to provide the necessary leadership.

\section{References}

1. Adapted from Hutchison GB: Evaluation of preventive services. J. Chronic Dis 1960; 11:497-508.

2. Peter G (ed): Report of the Committee on Infectious Diseases. 22nd Edition 1991. Elk Grove Village, Illinois: American Academy of Pediatrics. 1991.

3. National Center for Health Statistics. Health, United States, 1990. Hyattsville, Maryland: Public Health Service. 1991 Table 42.

4. Alford D, Kelly J, Halpin TJ, Nickey L, Crider R, Simpson DM et al: Retrospective assessment of vaccination coverage among school-aged children - Selected U.S. cities, 1991. Centers for Disease Control. MMWR 1992;41(6)103-107.

5. Centers for Disease Control. Morbidity and Mortality Weekly Report 1990;40(22): 369-372.

6. Hedrich AW: Monthly estimates of the child population 'susceptible' to measles, 1900-1931. Am J Hyg. 1933;17:613-630.

7. Schlenker TL, Bain C, Baughman AL, Hadler SC: Measles herd immunity: the association of attack rates with immunization rates in preschool children. JAMA 1992;267(6):823-826.

8. U.S. Department of Health \& Human Services. Public Health Service. Health Resources and Services Administration. Maternal and Child Health Bureau. Healthy Children 2000: National Health Promotion and Disease Prevention Objectives Re- 
lated to Mothers, Infants, Children, Adolescents, and Youth. DHHS Pub No HRSAM-CH 91-2. Washington, D.C.: U.S. Government Printing Office. 1991.

9. U.S. Department of Health and Human Services. Public Health Service. Healthy People 2000: National Health Promotion and Disease Prevention Objectives. DHHS Pub No (PHS) 911 -50212. S/N 017-001-00474-0. Washington, DC: U.S. Government Printing Office: 1991. P. 204-212.

10. Adapted from: Peter G (ed): Report of the Committee on Infectious Diseases 22nd Edition 1991. Elk Grove Village, Illinois: American Academy of Pediatrics. 1991. P. 17.

11. Universal Hepatitis B Immunization: Policy Statement. AAP News February 1992; $8(2): 14$

12. AAP News 1991:7(7):8.

13. Orenstein WA, Atkinson W, Mason D, Bernier RH: Barriers to vaccinating preschool children. J Health Care Poor Underserved. 1990,1:315-330.

14. AAP News $1991 ; 7(7): 6$.

15. The National Vaccine Advisory Committee: The measles epidemic: The problems, barriers, and recommendations. JAMA 1991;266(11):1547-1552.

16. Nassau RD: The costs of preventing measles. (letter) JAMA 1992;267(5):655-656.

17. Etkind P, Lett SM, Macdonald PD, Silva E, Peppe J: Pertussis outbreaks in groups claiming religious exemption to vaccinations. AJDC 1992;146:173-176.

18. Lewis T, Osborn LM, Lewis K, Brockert J, Jacobsen J, Cherry JD: Influence of parental knowledge and opinions on 12-month diphtheria, tetanus, and pertussis vaccination rates. $A D J C$ 1988;142:283-286.

19. Jones S: Missed opportunities. Texas Preventable Disease News. November 16 , $1991 ; 52(23): 1-2$.

20. Application Guidelines. The Robert Wood Johnson Foundation: ALL KIDS COUNT PROGRAM. Atlanta, Georgia: National Program Office: The Task Force for Child Survival and Development. 1992. P. 34. 